\title{
Central Canal of Spinal Cord
}

National Cancer Institute

\section{Source}

National Cancer Institute. Central Canal of Spinal Cord. NCI Thesaurus. Code C12891.

The hollow tube filled with cerebrospinal fluid that begins in the inferior portion of the fourth ventricle and runs the entire length of the spinal. 